\title{
A Research on how to Control the Risks of Construction Engineering Project in Construction Enterprises in China
}

\author{
Chenhua Cui \\ School of architecture, Xianyang Vocational Technical College, No 1 tongyi Road, Fengwei New \\ District, Xianyang City, Shaanxi Province, China. \\ E-mail: 1449202824@qq.com.
}

Keywords: Construction enterprise; Control; Risk; Project; Research

\begin{abstract}
In order to reduce risk of the construction engineering project in construction enterprises, through in-depth analyzing the current status and defects of construction engineering project's risk faced by construction enterprise at present in China, based on content analysis, qualitative and quantitative scientific methods, obtain the coping strategy and way of construction engineering project's risk, through practice find that the strategies and ways for construction enterprises bring vitality, economic and social benefits indeed.
\end{abstract}

\section{Introduction on Risk Management of Construction Engineering Project}

International aspects: In 1960s, it was vigorously system research, its research tendency was using the system approach to plan and control entirely the process of risk managements since 1980s, the development of theory research has been very quick. Domestic aspects: research started late, the research's method and angle is risk recognition and the risk analysis methodology from the technical angle, the research's method and angle is the systemic risks of the project methodology from an engineering angle, the research's method and angle is enterprise resource planning from the angle of the Organization. Also has some experience and the applied research in the actual engineering project, but application is limited in a certain local area of the project scope and In certain degree carries on analysis of the project's risk, because the research scope is very broad, in application aspect, also lacks certain systematic characteristic, the integrity and the specialization. And in the actual project implementation in our country, there are still some unharmonious factors which are not suitable for business operations, objectively caused some difficulties to the project risk management. [1]

\section{The Defects of Risk Control of Construction Project in China}

The Outer Layer, Macroscopic Defects of Risk Control of the Construction Engineering Project. Related Laws and Regulations System of Controlling Construction Project's Risk is Incomplete Hysteretic

Because operation of construction engineering project is jointly participatory processes of owner, contractor, design, supervision and so on, thus creating the complicated legal relationship of construction. Although at present our country successively has already appeared like "Law of insurance", "Guarantee Law", "Law of contract", "Building ordinance" and so on the laws, but its coverage is relatively narrow, the legal blank are many, can't very well restrain and regulate all kinds of activities and behavior of construction engineering project risk's control, reveal a legal lack of risk's control of construction project. Supporting laws, regulations and policies associated with the above law have many problems, one is between each level law, regulations and the policy's stipulation has not formed mutually supplement organic system, on the other hand the correlative policy also lacks the executive regulation, cannot instruct the risk management practice effectively. At the same time, due to the changing economic environment, new cases are frequent in construction field, but the corresponding laws and regulations lag behind, which makes legal guidance to the real economic activity is weak and inefficient. [2]

Risk Guarantee Mechanisms and Organizations of Construction Engineering Project are Missing 
Failed

Although the construction enterprises can adopt certain measures to avoid and reduce risks greatly, but when the force majeure occurs the construction enterprise's control often is not worthy of mentioning. This needs to play risk guarantee mechanism and guarantee ,compensation of having the qualification and financial strength of a third party - the guarantee organization, make construction enterprise risk loss is reduced to a minimum. But at present, due to limit and restriction of the country financial organ's developmental policy as well as financial enterprise own developmental situation of our country, which causes the flaw, not existence, the malfunction of the construction project's risk guarantee mechanism and the organization. Even if the traditional guarantee organization has the service of risk guarantee, but because the related service is often not the main service of guarantee organization, thus has not obtained very good development, the guarantee way, the specified amount already has not matched with the demand of construction industry's development. [3]

Specialized Intermediary Organizations Engaged in Risk Control of Construction Project is Missing

Continuously along with construction enterprise's grows and expands in our country, on the one hand it more and more independent undertakes the large-scale construction project, simultaneously withstands more risks. Although each construction project all needs the multitudinous participated main part composed of the owner, the design side, the construction side, the overseeing side and so on, also each main part all has own risk in the aspects of finance, technology, management and so on, but any main part is not the specialized risk control organization. When the project progresses to certain degree, anxious needs the specialized risk control intermediary organization to control the project risk in the entire life cycle. Overview of the current situation, yet there is no professional intermediary organizations of risk control of construction project in our country, although some project consultant firms have risk control service of the construction project at the same time, but it is the weakest and most despised in the company's business, this service has not yet developed the risk control consulting activity and the thing which may undertake independently. [4]

Risk Control Lack of Professional Talents in Construction Engineering Project

Risk control requirements practitioners have the ability of analyzing the economic and political situation, the ability of analyzing data and collecting information, and need the comprehensive skills of economy, management, law, technology, finance and many other aspects, in the related fields of finance, legal and engineering technology have a profound knowledge. Obviously in the employed domain there is an extremely high request for the employed talented person, this kind of high standard causes talented person that can really meet the needs of working positions is too few. In addition, in our country construction enterprises neglect and contempt risk control of construction project, which causes the building enterprises extremely low salary treatment level of the risk control's post, above two aspects cast professional talented person's deficiency of the construction project's risk control.

Inner Micro-Defects of Risk Control of Construction Project. The Risk Identification Methods' Efficiency is Miniscule

\section{Strategic Measures of Construction Enterprises Dealing with Construction Engineering Project Risk}

To Use Scientific and Comprehensive Risk Identification Methods Instead of the Imperfect Risk Identification Methods. Hierarchical Holographic Modeling(HHM) carries on recognition of the construction project's risk. Among them, "rank" refers to the understanding on what's wrong in which aspects of the system, "holographic" refers to when determining the system has a risk, risks should be identified by a system of multiple perspectives. Purpose of this method from many aspects, perspectives, views, dimensions and level captures and displays the internal level and different characteristics of a system, thus more comprehensively systematically presents single element intrinsic characteristic within a collection and link between individual elements. Using the HHM model, and through the expert brains storm law, carries on identification for the construction 
projec's t risk that construction companies possibly face, finally obtains the result.

Table 1 Low efficiency of risk identification method is embodied in the following aspects

\begin{tabular}{|c|c|c|}
\hline number & $\begin{array}{c}\text { aspect of low } \\
\text { efficiency }\end{array}$ & defects \\
\hline 1 & cost & $\begin{array}{c}\text { Spending too much money and manpower in the work, but the risk } \\
\text { identification's result is very difficult to play its due role for } \\
\text { subsequent risk control, which leads to high cost of risk identification }\end{array}$ \\
\hline 2 & $\begin{array}{c}\text { time } \\
\text { consumption }\end{array}$ & $\begin{array}{c}\text { Long cycle determines probable occurred risk is much in the process } \\
\text { of the project construction and operation, this kind of many and } \\
\text { dynamic, related risks at the time of identification need to spend more } \\
\text { time; when the lack of experience in risk identification, risk control } \\
\text { personnel, only can widely and generally analyze, judge, spent a lot of } \\
\text { time. }\end{array}$ \\
\hline 3 & reliability & $\begin{array}{c}\text { construction enterprise in the risk identification's process in our } \\
\text { country, has often spent the massive funds and the time, but the risk } \\
\text { identification' s result cannot let the persons be satisfied, thus which } \\
\text { casts poor reliability of risk identification . }\end{array}$ \\
\hline
\end{tabular}

The Defects of Risk Assessment Index System

Table 2 The defects of risk assessment index system

\begin{tabular}{|c|c|c|c|}
\hline number & $\begin{array}{c}\text { risk assessment } \\
\text { elements }\end{array}$ & gist & defects \\
\hline 1 & risk assessment & $\begin{array}{c}\text { mathematical analysis, } \\
\text { statistical analysis, } \\
\text { quantitative description } \\
\text { for risk factors }\end{array}$ & $\begin{array}{c}\text { overall development is relative lag, } \\
\text { concretely embodies that the } \\
\text { historical data of china' s construction } \\
\text { enterprises is deficient and subjective } \\
\text { probability which risk management } \\
\text { practitioners estimated is too strong }\end{array}$ \\
\hline 2 & risk appraisal & $\begin{array}{c}\text { indicators, criteria, } \\
\text { based on objective } \\
\text { circumstances, } \\
\text { appraisal is bad; estimate of the risk } \\
\text { level is inaccurate; the risk appraisal } \\
\text { benchmark and the risk level } \\
\text { qualitative description } \\
\text { for risk factors }\end{array}$ & \begin{tabular}{c} 
mathematics caliber is not unified. \\
\hline
\end{tabular} \\
\hline
\end{tabular}

To Optimize Risk Assessment Index System. Preliminary Evaluation of Construction Project's Risk

This phase of the assessment, primarily to filter out the unrelated risks with policy-maker responsibility or benefit, only in domestic demand given the scope of the responsibilities of policy makers and interest risk, only leave over the risk should be consider in the scope of policy-maker's responsibility and interest. [5]

The Double Standard's Assessment of Construction Project's Risk

In this stage, mainly using serious degree target of the risk result and possibility target of the risk occurrence to carry on generalized analysis, finally obtain the low risk, the general risk, the higher risk and the high risk four risk dimensions. make certain basis for the subsequent risk response.

To Increase the Flexibility of Responsing Risk. Making the risk response adjustment according to the objective environmental variation have obvious hysteresis, improving from following two points. If risk control personnel of the construction project regarding the risk - opportunity change, gives the positive prompt feedback, makes fast accurate risk response measure adjustment, enables the cost of the construction project to realize thrift, the time limit for a project can be reduced, the construction quality can be enhanced, or the profit space can be increased and 
so on, will be given the high quota reward of certain specified amount. If risk control personnel of the construction project regarding the risk - - opportunity change, doesn't give a positive feedback in a timely manner, but a negative response, and will be given the same degree of punishment, or even dismissed. [6]

To Strengthen Dynamic Mechanism of Monitoring Risk. To Regularly Monitor Project Risk.

Should regularly monitor project routine risks, especially for the project of core risk is distinguished, assessed and identified, as well as easy because of changes in the objective environment and major changes focus of periodic monitoring of the risk. And easy risk of occuring significant change due to the objective environment's change is carried on periodic key monitoring. Monitoring time-gap determination, then should carry on the targeted adjustment according to the different risk as well as the stage that the project is located. Risk monitoring work pays great attention to the key assurance principles, at the same time, also should have flexibility. Only balancing the monitoring time interval and monitoring behavior of monitoring the working effect it is highly efficient and beneficial to project construction operations. [7]

To Non-regularly Monitor Project Risk.

In the economical movement, can occur some unexpected thunderbolts frequently, these events do not have the omen, simultaneously often can have the significant influence to the project. To these thunderbolts, should implement the non-periodical project risk monitoring. Namely real-time attention economical event, after the significant event occurs, carries on immediately key recognition, appraisal and response for the correlation risk. In addition, it should be clear risk monitoring must include three parts's content of the data information's update and supplement, tracking of risk influence factor and adaptive adjustment of risk response.

To Stimulate Project Management Personnel to Control the Risk Consciousness. To Strengthen Risk Management Education, Ram Training of Staff Risk Management Knowledge

Through system training, increase risk control consciousness of construction project risk management personnel and ordinary staff. Under the guidance of the "help and lead" training objective and the four principles of guaranteeing the training's effectiveness, diversity, comprehensive, hierarchical and so on, training should be divided into two levels, one level is the general staff training, another is a risk management's professional training, and to ensure the effectiveness, diversity, hierarchy of the training; effectiveness of the training. By establishing training plan mechanisms, training feedback mechanism, training update mechanisms and other specific means to improve the effectiveness of the training. Diversity of the training. Through office cadres teaching, regular staff multi-level participation in teaching, internal training lecturer plan, the training of part-time lecturer diversification way to enhance the diversity of construction engineering project risk management training. Hierarchy of the training. Through all levels the training system's consummation including the operational level training, instructor level training, director-level training, specific hierarchical training carries on targeted training for ordinary employees and full-time employees engaged in construction project risk management training. [8]

To Perfect and Optimize Index of Risk Control Personnel's Performance Appraisal

Establishing a simple and effective risk control performance assessment index for risk management personnel and human resources professionals is of great significance. Meanwhile, to strengthen the incentive effect of performance appraisal for risk control personnel, establish personnel proportion of five performance ratings for outstanding, good, medium, the pending improves as well as lower than the standard and make a general stipulation, implement the lowliest place elimination series and the first place reward system, realize the optimization of construction project risk control team.

To Stablish the Scientific Consciousness of Risk Management

Owner,contractor and project supervising units and government departments all must have a full consciousness of risk management, carry out consciousness of risk management into all kinds of personnel to participate in the project; establish a sense of the whole process of risk management, There are various risk elements in the process of project implementation, and the risk is formed in the project's implementation; to establish legal consciousness of risk management, fulfill 
appointment according legal . Through legal means to solve the problem of defaults. [9]

To Perfect and Optimize the Laws and Regulations of Project Risk Control, Establishing and Consummating Risk Control System. Because of the framework of market economy system in China is not long, many systems are still in the exploratory stage, especially some existing laws and regulations are not adapted to project risk management. Lack of detailed rules for the implementation of the engineering insurance. At present, the key is to address outstanding problems existing in the field of construction, as soon as possible establish a reference to the international practice and conform to the actual engineering insurance and guarantee system in China. To study the reasonable engineering guarantee, engineering insurances fees standard and expenses levied on approach.

To Strengthen Guarantee Market's Cultivation, Positively Developing the Engineering Risk Management Intermediary Structure and Establishing Risk Management System. which is reality need of conforming to standardized and orderly development of market economy and avoiding risks, also need apply the means of market economy in the implementation of the system, strengthening nurture and guide for the market's construction. The establishment of the engineering guarantee system, in addition to continuly playing the role of the banks, should also actively cultivate other qualified institutions as the guarantor, to form a competitive insurance market.

To Regulate the Behavior of the Owners and Make the Business Management Really into the Orbit of Legal System. The exercise of administrative means and economic measures to regulate the behavior of the owner, is still a basic and effective method. Government management departments should strengthen law enforcement and supervision, strengthen its efforts to regulate the market, through reform and improvement of engineering quality supervision system, promote the owners' pay guarantee system, regulate the behavior of the owner. [10]

\section{Conclusion}

Through this exploration, I have felt that risk control of the construction engineering project has many new phenomenon, new problem which needs further research and solution. For example: how to carry on preparation's forecast for the risk's loss with the increase of engineering scale and the various associated factors; In the continuously change's domestic and international environment, people constantly improve the functional requirements of buildings, the emerge of new technologies, new crafts and new materials, which all can derive a lot of new risks. The people have not yet realized these new risks, we need further research and explore strategies to respond to these new risks.

\section{References}

[1] Q.J.Meng, Risk analysis and prevention of construction engineering, J. Infrastructure management and optimization. (2012) No.17, p.31-33.

[2] J.G.Gao, Study on risk management of engineering project, J. Market forum. (2006) No.4, p.81-82.

[3] W.X.Zheng, Discusses on risk management of the engineering project, J. Shaanxi construction. (2005) No.8, p. 51-52.

[4] M.Ling, Discusses on the effective way of the architectural engineering management shallowly, Science \& technology information. (2010) No.15.

[5] M.J.Han and S.J.Liu, planning and implementation of construction project management, Commodity and nature quantity. (2010) No.38.

[6] W.H.Li, Problems and innovation of construction management in our country, Commodity and quality. (2010) No.42.

[7] D.G.Li, To strengthen construction management to improve work efficiency, business 
conditions. (2010) No.23.

[8] C.X.Qiu, The existing problems and solutions in the management of construction, Modern science. (2010) No.8.

[9] R.H.Wang, Shallowly discusses on engineering contractors how to respond to project risks, J. Shaanxi construction. (2010) No.36, p.205-206.

[10] S.Q.Lei, Risk's management and insurance of International project, M.beijing: Chinese construction industry press.(2008). 